\title{
NORMAS TÉCNICAS PARA INDICAÇÕES GEOGRÁFICAS E SEUS REFLEXOS NO SETOR VITIVINÍCOLA
}

DOI: http://dx.doi.org/10.18616/pidi01

Kelly Lissandra Bruch - CEPAN/UFRGS E-mail: kellybruch@gmail.com Adriana Carvalho Pinto Vieira - PPGDS/UNESC E-mail: dricpvieira@gmail.com Ludimila Cesar Moura Gaspar - MAPA E-mail: ludimila.gaspar@agricultura.gov.br Cristiane Francisco da Silva - IFAL E-mail: cristianeSilva_9@hotmail.com Marcos Vinícius Araújo - CEPAN/UFRGS 


\section{INTRODUÇÃO}

O presente capítulo visa descrever o trabalho de elaboração de normas técnicas sobre Indicação Geográfica (IG) por meio de uma parceria firmada entre a Associação Brasileira de Normas Técnicas - ABNT e o Serviço Brasileiro de Apoio às Micro e Pequenas Empresas - SEBRAE e demonstrar como essas instituições podem auxiliar na estruturação, no reconhecimento e no desenvolvimento sustentado das IGs no Brasil, notadamente no campo das IGs vitivinícolas. Atualmente, encontram-se publicadas duas normas: a Norma Brasileira ABNT NBR n 16.479-2016, denominada Indicação Geográfica - Terminologia, e a Norma Brasileira ABNT NBR n 16.536-2016, denominada Indicação Geográfica - Orientações para estruturação de uma Indicação Geográfica para produto. Encontram-se em fase de elaboração a norma técnica que aborda sobre o controle das IGs e a norma técnica que trata do sistema de gestão de IG.

A Comissão Especial de Estudos de Indicações Geográficas - CEE-IG, que se reuniu mensalmente nos últimos dois anos e meio para a elaboração dessas normas, é composta de representantes dos produtores das IGs, das associações que fazem a gestão das IGs, de entidades que representam setores relacionados a produtos com IG, de órgãos reguladores como o Ministério da Agricultura, Pecuária e Abastecimento (MAPA) e o Instituto Nacional da Propriedade Industrial (INPI), entre outros. A finalidade desse estudo é demonstrar, no âmbito do setor vitivinícola, se essas normas podem auxiliar na estruturação e no reconhecimento de novas Indicações Geográficas (IGs), bem como no desenvolvimento sustentado das IGs reconhecidas. Os resultados ainda não são conclusivos, mas podem apontar um auxílio na estruturação das IGs em fase de reconhecimento, bem como uma facilitação na compreensão dos produtores sobre o que seriam as IGs.

O capítulo está dividido em seis partes. A primeira é esta introdução. Na segunda, faz-se uma breve revisão das Indicações Geográficas no Brasil e da Comissão Especial de Estudos da ABNT sobre Indicações Geográficas - CEE-IG. Na terceira parte, é apresentada a metodologia de construção das normas técnicas. Na quarta, a influência das normas técnicas no setor vitivinícola. $\mathrm{Na}$ quinta parte, apresenta-se a metodologia utilizada no presente estudo. Na sexta e última parte, os resultados e considerações finais. 


\section{BASES TEÓRICAS: INDICAÇÃO GEOGRÁFICA}

No âmbito da criação da Organização Mundial do Comércio (OMC), é aprovado o acordo sobre Aspectos dos Direitos de Propriedade Intelectual Relacionados ao Comércio (ADPIC), mais conhecido pela sigla em inglês TRIPS (Trade Related Aspects of Intellectual Property Rights). Dentre os institutos jurídicos regulados, encontra-se a Indicação Geográfica.

As IGs são instituições mais conhecidas na Europa e ainda pouco notáveis na América do Sul. No continente europeu, a concessão da primeira proteção legal é datada de 1756. O uso de nomes geográficos se consolidou como referência para os mercados, independentemente da formalização permitida pela proteção legal, com o objetivo de proteger os fabricantes de produtos de destaque associados a uma região específica e evitar a usurpação de um nome consagrado do que efetivamente assegurar a identificação de um produto com características diferenciadas; buscar vantagens competitivas; e valorizar o local originário do referido bem (BRUCH, 2013; VIEIRA; BUAINAIN; BRUCH, 2015; VIEIRA; PELLIN, 2015; VIEIRA; WATANANE; BRUCH, 2012).

No âmbito brasileiro, a identificação dos produtos pela sua origem geográfica ocorre há poucas décadas. A primeira IG para o reconhecimento da Indicação de Procedência Vale dos Vinhedos data de 2002 (BRASIL, 2002). A partir dessa década, o tema vem despertando grande interesse de diversas cadeias produtivas e instituições de fomento, pesquisa e extensão na busca por conhecimento sobre o papel das IGs e dos reconhecimentos das regiões notoriamente reconhecidas. Consequentemente, o número de indicações geográficas oficialmente reconhecidas vem aumentando, visto que até o fechamento desta publicação constavam 59 IGs registradas no Instituto Nacional da Propriedade Industrial - INPI (BRASIL, 2002).

A Lei de Propriedade Industrial (LPI), Lei $n^{\circ}$ 9.279/96 (BRASIL, 1996), em seu texto, não define o que é uma IG, mas a classifica em duas modalidades: Indicação de Procedência (IP) e Denominação de Origem (DO).

De acordo com o art. 177 da LPI, a IP é conceituada como: "[...] o nome geográfico de país, cidade, região ou localidade de seu território, que se tenha tornado conhecido como centro de extração, produção ou fabricação de determinado produto ou de prestação de determinado serviço." (BRASIL, 1996, n.p.). Para Locatelli e Souza (2016), o elemento característico é a notoriedade do meio 
geográfico de origem relacionado ao produto/serviço. No entanto, no Brasil, apesar de não haver a exigência legal, as autoras apontam que os pedidos de IP têm, em regra, relação com produtos que envolvem tradição e possuem vínculo com a cultura local. Também não há qualquer exigência normativa relacionada à qualidade ou à característica do produto vinculado ao meio geográfico de origem, bastando que o nome geográfico seja reconhecido.

Quanto à DO, a LPI (art. 178) a define como: "[...] o nome geográfico de país, cidade, região ou localidade de seu território, que designe produto ou serviço cujas qualidades ou características se devam exclusiva e essencialmente ao meio geográfico, incluídos fatores naturais e humanos." (BRASIL, 1996, n.p.). Para a comprovação desse ativo, há a exigência de demonstração do vínculo de uma característica ou qualidade do produto com o meio geográfico. 0 resultado esperado é que os produtos da região reconhecida como DO sejam diferenciados, ou até mesmo únicos, distintos dos demais em razão do meio geográfico, incluindo fatores naturais e humanos, conforme apontam Locatelli e Souza (2016).

Segundo Vieira, Watanabe e Bruch (2012), o conceito de IGs está relacionado a produtos com origem geográfica definida. Ao vincular o produto à sua origem geográfica e tornar as qualidades e características próprias da identidade e cultura da região visíveis ao mercado, estabelece-se o mecanismo de valoração do ativo intangível. Segundo Pecqueur (2009), a capacidade de utilização dos recursos territoriais e a transformação destes em valor são consideradas as externalidades positivas do território.

O instituto jurídico da IG possibilita preservar características do produto e da região, bem como transformar os ativos intangíveis, como a reputação, os fatores ambientais específicos e as competências humanas em valor econômico (VIEIRA; ZILLI; BRUCH, 2015).

Para reconhecer uma IG, é observado o disposto na LPI e nos acordos internacionais, especialmente o TRIPS. Ainda, a LPI dispõe que o INPI estabelecerá as condições para o registro. A atual normativa que rege tais condições é a Instrução Normativa INPI n 25/2013 (BRASIL, 2013).

A referida IN define critérios de qualidade, direitos e deveres dos produtores nacionais que requerem a proteção. Para requerer o registro, são legitimadas as associações, os institutos ou as pessoas jurídicas que representem a coletividade. Dessa forma, na prática, quem realmente faz a gestão das IGs geralmente são os produtores a ela vinculados. 
Em seu art. 6, são estabelecidos os requisitos para instrução do processo no órgão competente do Instituto Nacional de Propriedade Intelectual (INPI), entre eles: o formulário de pedido de registro de IG, no qual deve constar o nome geográfico e a descrição do produto ou serviço; o instrumento que comprove a legitimidade do requerente ou da instituição que representa os produtores ou prestadores de serviço; o Regulamento de Uso (RU) do nome geográfico, o qual descreve as normas relativas ao uso do signo distintivo; o documento oficial de delimitação da área geográfica; a representação gráfica; a procuração, quando se fizer necessária; e o comprovante de pagamento da taxa correspondente.

De acordo com Vieira, Buainain e Bruch (2015), ao longo dos últimos anos, a sociedade tem demonstrado uma maior conscientização quanto à importância das questões sociais e ambientais relacionadas à forma de produção e comercialização de produtos agroalimentares. Há percepção de que as ações de políticas públicas direcionadas apenas para o aumento da produção, apesar de serem importantes, já não são mais suficientes para o mercado, cada vez mais globalizado e competitivo.

Wilkinson (2008) revela que a reorganização social e política no campo e a mudança de paradigma da produção agrícola, a partir da década de 1990, foram determinantes para o surgimento de um conjunto de novos mercados e do consumo alimentar baseado na valorização do produto por qualidades e características específicas, como o mercado de nicho, de produtos artesanais e orgânicos, solidário e de origem.

Diante da tendência crescente de valorizar o patrimônio imaterial vinculado aos territórios, a IG pode ser considerada um instrumento de apoio ao desenvolvimento territorial e de diferenciação de produtos/serviços. Segundo Nierdele (2013), o registro da IG é um importante instrumento de estratégia para a indução do desenvolvimento territorial rural, por estimular os atores locais e promover "processos de qualificação". Isso ocorre, segundo o autor, pelo fato de ensejar a revalorização de tradições, costumes, o saber fazer e outros bens imateriais associados a uma identidade territorial e à origem geográfica específica, além de novas práticas para agregação de valor e acesso a novos mercados.

Outros benefícios também precisam ser considerados nos projetos voltados ao reconhecimento de IGs. De acordo com Cerdan et al. (2014), as IGs podem gerar benefícios sociais e culturais representados pela inserção de 
produtores ou regiões desfavorecidas no mercado, como também prover benefícios ambientais relacionados à preservação da biodiversidade e dos recursos genéticos locais.

Locatelli (2007) corrobora as afirmações de Pecqueur (2001) ao defender que é possível observar o desenvolvimento e o fortalecimento de atividades voltadas ao turismo e à gastronomia em muitas regiões que obtiveram o reconhecimento de IGs para seus produtos como, por exemplo, a Indicação de Procedência Vale dos Vinhedos. Para a autora, as IGs, ao estimularem a tradição e a cultura de uma região, atraem turistas e possibilitam a exploração de atividades lucrativas indiretas.

Em pesquisa realizada por Pellin e Vieira (2016), na qual abordaram sobre as perspectivas das IGs após a concessão do registro, os autores destacam três vantagens: (i) o aumento na produção de produtos não atrelados diretamente à IG, mas que acabam sendo beneficiados; (ii) o reconhecimento pelo consumidor da relação entre produto e território; e (iii) a inserção de inovações nos produtos reconhecidos.

Em relação à primeira vantagem, a pesquisa confirma a capacidade das IGs de estimular atividades complementares na região demarcada que, muitas vezes, não têm relação direta com o produto reconhecido, no entanto são beneficiadas. É o que Pecqueur (2001, p. 45) classifica como "cesta de bens e serviços do território". O consumidor, ao se interessar em adquirir produtos com IG, pode se interessar também em consumir outros produtos e serviços provenientes daquela região demarcada e, assim, estimular a produção e oferta de outros bens (PELLIN; VIEIRA, 2016). No mesmo sentido, Flores (2006) cita que o reconhecimento de Indicação Geográfica, seja IP ou DO, é uma potencial estratégia de desenvolvimento de uma cesta de bens do território, valorizando um conjunto de produtos locais, sejam econômicos, sociais e ambientais. Corroboram esse mesmo pensamento Vieira e Pellin (2015), observando que na maioria dos casos as Indicações de Procedência e as Denominações de Origem podem induzir o desenvolvimento de outros segmentos que não tenham relação direta com o produto.

A segunda vantagem aponta o reconhecimento pelo consumidor de questões relacionadas além das qualidades intrínsecas ao produto, estimuladas pela IG, ao relacionar produto com o território. O produto da IG possui qualidades vinculadas ao meio geográfico e componentes da identidade territorial que o diferencia de outros produtos similares (PELLIN; VIEIRA, 2016). 
Nos produtos de IG são identificados critérios subjetivos do meio geográfico e da identidade e cultura local. Essas características são determinantes à nova dinâmica de consumo e do mercado da emoção, em que são oferecidos, além de um produto, memórias de experiências vividas em dado tempo ou espaço, estando presentes os ativos territoriais e a identidade cultural de dada região (GASPAR, 2015).

Por fim, a terceira vantagem apontada sugere uma relação com o sistema de produção. A partir do momento em que as regras para produção são transcritas no Regulamento de Uso, a tendência é que sejam estabelecidos controles internos e externos, como também incorporadas inovações, sejam tecnológicas na linha de produção quanto nos processos de gerenciamento (organizacionais) e de posicionamento de mercado, com marketing e divulgação. A contribuição do processo coletivo e a democratização dos processos de decisão conjugam na melhoria do processo produtivo sem alterar a tipicidade do produto e também refletem na possibilidade de redução de custos operacionais (GASPAR, 2015).

Ainda de acordo com a pesquisa realizada por Pellin e Vieira (2016), em relação às contribuições das IGs para o desenvolvimento territorial, destacaram-se três vantagens: (i) o aumento no fluxo de turistas; (ii) o aumento das vendas dos produtos; e, apontadas com o mesmo percentual; (iii) o aumento no número de estabelecimentos na região da IG e valorização das terras e propriedades na região demarcada. Todas as vantagens se relacionam com a dimensão econômica. Nesse contexto, o fortalecimento de atividades para os turistas merece destaque. Trata-se de uma atividade que é estimulada na maioria das experiências de IG vitivinícolas no Brasil e no mundo.

Um exemplo de que a IG pode contribuir para o desenvolvimento territorial é observado no Vale dos Vinhedos, haja vista o aumento considerável no fluxo turístico na região demarcada que recebeu, em 2014, de acordo com a Associação dos Produtores de Vinhos Finos do Vale dos Vinhedo (APROVALE), 290 mil turistas. A título de comparação, em 2006, o fluxo de turistas foi de apenas 45 mil. São 26 vinícolas da IG. Os perfis são variados: há vinícolas familiares, com elaboração limitada e venda exclusiva em seu varejo, como também grandes empresas com presença internacional. São 43 associados ligados ao negócio do turismo entre nove hotéis e pousadas, sendo um SPA internacional, 15 restaurantes, duas agências de turismo, uma operadora de viagem, agroindústrias de queijos, geleias, biscoitos, ateliês de arte e artesanato, showroom de indústria 
moveleira, entre outros. Portanto, é importante lembrar que a atividade turística produz benefícios diretos e indiretos para vários segmentos, gerando emprego e renda local. Isso demonstra que novas perspectivas para a região foram abarcadas no processo de reconhecimento da IG, porém não só para o setor vitivinícola.

Entretanto, de acordo com Pellin e Vieira (2016), há a necessidade de um esforço maior de aproximação entre os diversos stakeholders (setor público, setor privado e sociedade) para que todos os envolvidos, bem como o território, possam usufruir dos possíveis benefícios que a IG permite. É necessário construir e fortalecer as parcerias, para que possam auxiliar no desenvolvimento estratégico da IG e receber apoio do setor governamental, a fim de que políticas públicas sejam elaboradas para maior apoio pós-concessão do registro da IG (PELLIN; VIEIRA, 2016).

Atualmente, algumas IGs apresentam resultados bastante expressivos como, por exemplo, o Vale dos Vinhedos. Mas esses resultados não podem ser "romantizados" a ponto de acharem que a IG produz resultados positivos automaticamente. Pelo contrário, conforme aponta o presidente da Associação dos Produtores de Uva e do Vinho Goethe - PROGOETHE, foi após três anos do reconhecimento da Indicação de Procedência dos Vales da Uva Goethe que o trabalho aumentou, determinado por novos desafios e demandas. Manter a coerência e a adesão de todos os associados e a participação dos stakeholders locais e externos ao território para que o turismo na região seja reconhecido não é uma tarefa fácil (PELLIN; VIEIRA, 2016).

Nesse sentido, uma interessante iniciativa tem despertado a atenção no âmbito das IG. Trata-se da proposta de se elaborarem normas técnicas para sistematizar as melhores práticas para a estruturação do projeto para a gestão e o controle das IGs. Essa iniciativa está sendo realizada por meio de uma parceria firmada entre a Associação Brasileira de Normas Técnicas - ABNT e o Serviço Brasileiro de Apoio às Micro e Pequenas Empresas - SEBRAE, e está mais detaIhado no tópico a seguir. A ABNT representa o Brasil na Organização Internacional de Normalização - ISO, internalizando padrões internacionais de normalização, bem como levando iniciativas brasileiras para o âmbito internacional. 


\section{A COMISSÃO ESPECIAL DE INDICAÇÃO GEOGRÁFICA}

Com a motivação de resolver problemas relacionados à incorporação de qualidade, à eficiência e às melhores práticas, bem como aumentar a competitividade de pequenas e médias empresas (MPE), em 2007, a ABNT e o SEBRAE celebraram um convênio que visava promover o envolvimento das MPE com a normalização (OLIVEIRA, 2013). O êxito obtido nessa parceria resultou na manutenção do convênio que, até o momento da elaboração desta publicação, mantém-se em execução (ABNT, s.d.; OLIVEIRA, 2013).

O escopo dessa parceria prevê diversas ações relacionadas à elaboração e à implementação das normas técnicas pelas MPE. Dentre elas são incluídas ações de levantamento de demandas setoriais para o desenvolvimento das normas técnicas, com apoio à participação das MPE nas reuniões das comissões nacionais. Ainda, é prevista a capacitação na aplicação das normas técnicas, bem com a promoção ao acesso à norma técnica a partir da venda subsidiada (SEBRAE, 2015).

As normas técnicas contemplam os segmentos de mercado relacionados a produtos, a serviços, às competências de pessoas e a procedimentos (SEBRAE, 2015). O processo de elaboração de normas técnicas é baseado em participação voluntária de especialistas, sendo incluído nesse conceito a participação do dono do negócio/empresário/empreendedor, instituições públicas e privadas vinculadas ao respectivo segmento, consumidores e outros que tenham interesse na elaboração e na aplicação da norma.

No âmbito dessa parceria, o SEBRAE percebeu a possibilidade de estabelecer normas técnicas nos projetos voltados ao reconhecimento de Indicações Geográficas brasileiras. Assim, para confirmar a necessidade de elaboração, nos meses de abril e maio de 2014, foram realizadas duas Oficinas de Trabalho com produtores e entidades vinculadas ao processo, fomento, registro, apoio e pesquisa sobre IG para levantamento de demandas. Essas reuniões foram realizadas em Bento Gonçalves (RS), com 21 participantes, e em Belo Horizonte (BH), com 23 participantes, respectivamente.

O resultado dessas oficinas foi a confirmação da necessidade de criação de normas técnicas para o sistema de Indicação Geográfica brasileiro e o encaminhamento à ABNT para a formação do Comitê Técnico. Inicialmente, houve a concordância entre os participantes das duas reuniões para a elaboração de normas referentes à terminologia e para a gestão de governança. 
A reunião de instalação da Comissão de Estudos Especiais de Indicação Geográfica - ABNT/CEE-216 foi realizada em julho de 2014, na cidade do Rio de Janeiro. Contou com a presença de 25 representantes de produtores, consumidores e instituições governamentais reguladoras, de fomento e de pesquisa. Para o escopo do trabalho, foi estabelecida a elaboração de quatro normas técnicas: Terminologia, Estruturação de Indicação Geográfica, Gestão de Indicação Geográfica e Controle de Indicação Geográfica.

A finalidade de criar normas técnicas para o sistema de Indicação Geográfica é contribuir com diretrizes para orientação nos processos voltados ao reconhecimento de Indicações Geográficas no Brasil, no que tange à terminologia, à estruturação, à gestão e ao controle das IGs brasileiras. As normas técnicas são de aplicação voluntária e atuam em caráter complementar às normativas existentes no INPI para o reconhecimento de uma Indicação Geográfica. Vale ressaltar que, no Brasil, não há regulamentação específica para a fase posterior ao reconhecimento da IG, tanto nas questões relacionadas à extinção ou à anulação de uma IG reconhecida, quanto no âmbito de seu controle e gestão.

No âmbito do convênio ABNT-SEBRAE, são beneficiados com apoio na participação das reuniões os participantes e representantes de IGs reconhecidas. A democratização na participação de especialistas em forma multidisciplinar e multi-institucional para a elaboração das normas técnicas permite que estas sejam elaboradas de forma acessível a técnicos, a produtores e aos demais interessados.

Importante ressaltar que, até o término da elaboração deste capítulo, duas normas técnicas encontram-se publicadas, notadamente a Norma Brasileira $n^{\circ} 16.479$, publicada em 08/09/2016, sob a denominação Indicação Geográfica - Terminologia (ABNT, 2016a), e a Norma Brasileira $\mathrm{n}^{\circ}$ 16.536, publicada em 25/10/2016, sob a denominação Indicação Geográfica - Orientações para a estruturação de Indicação Geográfica para produto (ABNT, 2016b). As normas para gestão e controle de IGs ainda estão em processo de elaboração.

\section{METODOLOGIA DA CONSTRUÇÃO DA NORMA}

As normas técnicas são construídas essencialmente no âmbito da Comissão de Estudos Especiais sobre Indicação Geográfica (CEE-IG). Para cada tema, é constituído um comitê específico com participação de multiprofissio- 
nais, representantes de toda a cadeia produtiva e de consumidores neutros, como universidades, laboratórios, institutos, governos, partes interessadas, dentre outros. Um dos aspectos mais importantes na construção da norma é o princípio da transparência e livre acesso das partes interessadas no processo da construção.

O processo de construção de uma norma utiliza o conceito universal baseado no ciclo PDCA (Planejar, Fazer, Verificar e Agir). Partindo desse conceito, a construção da norma foi realizada com as seguintes etapas:

\section{Planejar}

Essa etapa foi iniciada com a reunião de instalação da Comissão de Estudos Especiais - ABNT/CEE 216, que ocorreu em 22 de julho de 2014, na sede da $A B N T$, no Rio de Janeiro. A reunião foi organizada pela $A B N T$, com registro em ata sobre as discussões realizadas. Em resumo, as atividades de planejamento para as atividades da CEE-IG seguiram os tópicos:

- Publicação e envio de convites para as partes interessadas;

- Abertura da reunião por representante da ABNT;

- Apresentação sobre a importância da construção da norma e justificativa referente à relevância do tema para a sociedade;

- Apresentação dos participantes presentes na reunião e justificativa dos convidados ausentes;

- Escolha do(a) coordenador(a) da CEE-IG pelos membros presentes na reunião;

- Elaboração do programa de trabalho;

- Definição do cronograma de trabalho e prazos;

- Definição e priorização dos temas das normas a serem construídas. Para o programa de trabalho, foi definida a elaboração de quatro normas técnicas relativas à Terminologia da Indicação Geográfica (216:000.00-001), Diretrizes para a Estruturação de uma Indicação Geográfica (216:000.00-002), Gestão de uma Indicação Geográfica - Boas práticas (216:000.00-003) e Rastreabilidade e Mecanismo de Controle (216:000.00-004). 


\section{Fazer}

Essa etapa se refere à fase de elaboração dos conteúdos das normas técnicas. É a que demanda conhecimento técnico e prático, levantamento bibliográfico, elaboração de textos, discussões técnicas, organização e trabalho em equipe, entre outros. Nela, ocorre a construção de textos de forma participativa e colaborativa, que são denominados inicialmente como projetos de normas, que formarão, na sequência, o texto da norma. É importante ressaltar que a norma não é feita por uma pessoa, mas sim por um grupo diversificado de pessoas que votam e validam todo o texto antes do processo de consulta pública e publicação. Todos podem e devem opinar, justificando suas sugestões e propostas de mudanças, devendo ser aceitas sem haver distinções por peso ou outro critério.

O conjunto de participantes reunidos, denominados Comissão Especial de Estudo, pesquisa, apresenta e discute o texto até chegar a um consenso sobre o texto final.

As reuniões presenciais da ABNT/CEE 216 ocorrem em intervalos de 30 a 60 dias, conforme o cronograma elaborado pela comissão, validado e publicado por meio de ata. As reuniões presenciais são itinerantes, permitindo que as partes interessadas de diferentes regiões possam participar das discussões e da construção dos textos das normas. Ao mesmo tempo, todos os membros recebem as informações e encaminhamentos das reuniões e podem contribuir para a elaboração das normas, mesmo não participando das reuniões presenciais. Isso pode ser realizado tanto por e-mail quanto pelo sistema disponibilizado, denominado Livelink, no qual todas as atas ficam disponíveis, bem como todo o conteúdo discutido em reunião, as versões dos projetos de norma, os materiais complementares que auxiliam os participantes na construção do conhecimento necessário para a elaboração da norma.

A composição da CEE-IG inclui produtores das IGs; representantes de seus grupamentos coletivos; representantes de instituições públicas ou privadas que desenvolvem atividades de apoio e pesquisa; órgãos públicos regulamentadores da IG; e consumidores dos produtos das IGs.

Como método para agilizar as discussões e a construção dos textos das normas de forma concomitante, os membros foram convidados a se dividirem em subgrupos de trabalho, denominados GT, havendo para cada grupo um res- 
ponsável em consolidar os textos recebidos para apresentar, presencialmente, nas reuniões. Assim, foram criados três GTs: GT de Estruturação, GT de Controle e GT de Gestão. Esse método facilitou o processo de construção do texto de forma colaborativa e com maior agilidade. A norma de Terminologia foi elaborada em conjunto com o grande grupo durante todas as reuniões.

O sucesso, nessa fase, ocorreu de forma sistemática e orgânica, com a participação de um número expressivo de sugestões. A dinâmica de construção colaborativa e consensual ocasionou maior produtividade em menor tempo.

\section{Verificar}

No contexto de metodologia de trabalho, a etapa de verificação é atribuída a três processos, a saber: revisão final do projeto de norma pela CEE-IG, revisão ortográfica pela ABNT e submissão do texto para consulta nacional. A relevância, nessa fase, é a participação social para a avaliação do texto aplicado, cabendo a indicação em três opções de voto:

- Aprovação - indica que o texto apresenta conteúdo técnico condizente para o escopo da norma. Assim, não há necessidade de alteração e o texto segue para publicação como norma.

- Aprovação com alteração de forma - indica que há aprovação do conteúdo técnico da norma, porém com necessidade de alteração do texto com a finalidade de apresentar maior clareza nas informações. Nessa opção de voto, o participante deve apresentar a(as) proposta(s) de alteração(ões) e justificar tecnicamente cada uma.

- Reprovação - indica que o texto não possui conteúdo técnico suficiente para o escopo da norma. Como no item anterior, o participante deve justificar tecnicamente a razão que reflete a recusa da publicação desse texto como norma.

A consulta nacional permite que as partes interessadas que não estavam presentes nas discussões dos textos da norma possam se manifestar. Dessa forma, é dada a oportunidade para todos opinarem e validarem o documento antes de sua publicação. São disponíveis 60 dias para a manifestação pública. 
A norma de Terminologia foi submetida à Consulta Nacional em 04 de fevereiro de 2016, após 18 reuniões presenciais, que contaram com a presença de 73 pessoas durante as suas realizações.

A norma de Estruturação foi submetida à Consulta Nacional em 14 de junho de 2016, após 19 reuniões presenciais, que contaram com a presença de 61 pessoas durante as suas realizações.

O trabalho minucioso e metódico da CEE-IG nas fases de planejamento, execução e verificação tem como propósito a elaboração de normas técnicas com aplicação plena e satisfatória para as Indicações Geográficas.

\section{Agir}

Essa fase é determinada pela análise dos votos da consulta pública e tomada de decisão para o texto de norma.

Encerrada a consulta nacional, os votos são consolidados pela ABNT e encaminhados para apreciação pela CEE-IG em uma reunião presencial e específica para essa finalidade. A CEE-IG avalia os votos, os comentários e as justificativas recebidos. Cabe à comissão aceitar ou rejeitar as proposições recebidas, mediante razão técnica e consenso entre os membros. Após a análise dos votos, a CEE-IG realiza a tomada de decisão sobre a indicação do texto de norma para a publicação.

No caso em que a publicação da norma é formalizada, seu acesso é disponibilizado para toda a sociedade mediante a venda. Seu valor é calculado a partir do número de páginas.

Cabe ressaltar que, devido ao convênio ABNT-SEBRAE, o custo das normas é subsidiado para as MPE. A ABNT possui como prática a análise periódica da norma. Assim, havendo a necessidade de revisão, o processo é aberto para que a comissão possa realizar o processo de melhoria contínua.

Como resultado, após a norma de Terminologia ter sido submetida à Consulta Nacional, ela retornou à Comissão Especial de Estudo, que avaliou todos os comentários, um total de 22 manifestações, e, acatando diversas sugestões, recomendou a publicação final, que ocorreu em 08/09/2016, sob a seguinte nomenclatura: Norma Brasileira $\mathrm{n}^{\circ} 16.479$, sob a denominação Indicação Geográfica - Terminologia (Geographical Indication - Terminology). 
A norma de Estruturação, após ser submetida à Consulta Nacional, retornou à Comissão Especial de Estudo, que avaliou todos os comentários, acatando diversas sugestões, e recomendou a publicação final, que ocorreu em 25/10/2016, sob a seguinte nomenclatura: Norma Brasileira $n^{\circ} 16.536$, sob a denominação Indicação Geográfica - Orientações para estruturação de Indicação Geográfica para produto (Geographical Indication - Guidelines for structuring of Geographical Indications for product).

\section{DESENVOLVIMENTO SUSTENTÁVEL DE INDICAÇÃO GEOGRÁFICA PARA O VINHO BRASILEIRO}

Assim como em outros países, o vinho, no Brasil, foi o primeiro produto a ter uma Indicação Geográfica reconhecida. Trazido a partir da colonização europeia, essa antiga cultura se estabeleceu no País e ganhou características específicas desse terroir. Desenvolveu sua própria identidade e consolidou-se, seja pela tradição, paisagem, ou por ser um produto que colabora e colaborou para o desenvolvimento de produtores e regiões ao longo da história no Brasil.

Ao ser reconhecida uma Indicação Geográfica no setor vitivinícola, isso traz visibilidade a esse produto, fazendo com que seja colocado sob o olhar de seus consumidores para que conheçam seus processos, sua identidade e o local em que é produzido, assim como o seu contexto. Esses signos distintivos protegem produtos tradicionais locais, a estrutura social e econômica de onde estão inseridos, mostrando, assim, uma origem distintiva, com identidade territorial e que traz segurança à comunidade, além de desenvolver mercados (ILBERY et al., 2005). Ilbery et al. (2005) completam que tudo isso se baseia em três importantes fatores: produto, processo e lugar (território), com qualidades intrínsecas ao lugar, práticas ambientais, técnicas de fabricação, processos tradicionais, entre outros.

Ao estabelecer a vinculação desses três fatores, a Indicação Geográfica traz consigo a noção do terroir, a qualidade de um produto agrícola, práticas culturais, conhecimento dos produtores e recursos locais que colaboraram para aquela produção (BOWEN, 2010).

Para o vinho brasileiro, essas práticas atestam sua identidade e características desse terroir, seja por ser uma vitivinicultura tropical, com identidade 
e características edafoclimáticas específicas, com vinhos de regiões tropicais e com paisagens e terroirs particulares, montanhas, vales e savanas que expressam valores de importantes biomas brasileiros.

Em aspectos sociais e econômicos, a expressão do terroir, da identidade local e da tradição no vinho anuncia a manutenção dos vitivinicultores no campo, o desenvolvimento regional e social, a atração de turistas, proporcionando a interação dos agricultores e permitindo a visibilidade de produtos genuínos no mercado. Os consumidores buscam nesses produtos reconhecidos por IGs características tradicionais, percebem a qualidade e estão dispostos a pagar por um produto premium (SOAM; HUSSAIN, 2011), podendo proporcionar crescimento econômico para os produtores e a região. Contudo, ainda há muito a se desenvolver para o reconhecimento de Indicações Geográficas no Brasil, principalmente por ser algo relativamente recente em algumas áreas e regiões.

Há particularmente grandes questões relacionadas com a estruturação efetiva e duradoura de uma IG. O procedimento de reconhecimento formal é apenas uma dessas etapas, posto que a construção efetiva de uma trajetória que abarque todos os elementos necessários para que a IG seja reconhecida e tenha uma saudável continuidade após esse reconhecimento ainda se constitui em um dos grandes óbices aos processos de IG.

Dentre os 59 pedidos de reconhecimento concedidos no Brasil até o fechamento deste capítulo, 41 são para Indicações de Procedência e 18 para Denominações de Origem. Destas, muitas ainda não alcançaram efetivamente o mercado, em especial por questões estruturais, de implementação do controle e gestão da IG. Destas, há uma Denominação de Origem para vinhos brasileiros - Vale dos Vinhedos - e seis Indicações de Procedência para vinhos brasileiros - Vale dos Vinhedos, Pinto Bandeira, Farroupilha, Monte Belo, Altos Montes e Vales da Uva Goethe. No caso das IGs vitivinícolas, o percentual de IG que efetivamente têm colocado produtos no mercado é bem maior se for feita uma análise proporcional ao número de IGs reconhecidas. Apenas uma delas ainda não apresentou produtos controlados. Nesse sentido, por um lado, a participação de representantes das IGs vitivinícolas na Comissão Especial de Estudos tem sido fundamental para uma adequada construção dessta norma, baseada especialmente nos casos em que se pode verificar um efetivo sucesso.

É nesse sentido que a Comissão de Estudo Especial de Indicação Geográfica da ABNT desenvolveu as duas primeiras normas, a primeira sobre as 
Terminologias e a segunda sobre a Estruturação de uma Indicação Geográfica para Produto. O objetivo é justamente dar suporte para a estruturação da IG desde seu nascedouro, além de permitir a consolidação de um vocabulário comum a todas as IGs.

Deve ser ressaltado que, no Brasil, a legislação é bastante singela com relação à regulação do reconhecimento de uma IG, fazendo-se necessária a elaboração de um suporte onde os produtores possam colher informações sobre as melhores práticas relacionadas à sua estruturação. Com esse propósito, as normas técnicas são elaboradas para servir de recurso complementar à legislação.

As normas que, no momento, estão em fase de elaboração, notadamente relacionadas ao controle e à gestão da IG, objetivam permitir que, após reconhecidas, haja uma efetiva continuidade no processo da IG, evitando-se que muitas surjam natimortas.

\section{RESULTADO}

O trabalho se desenvolveu mediante uma análise exploratória do artigo que está sendo realizado na elaboração das normas técnicas aplicadas às IGs no âmbito da Comissão Especial de Estudos de Indicações Geográficas (CEE216) da ABNT. A pesquisa se baseou na revisão da literatura sobre Indicações Geográficas, bem como em todo o material produzido até o presente momento pela CEE-IG, disponível a todos os participantes por meio da plataforma Livelink.

A partir dessa perspectiva, fez-se uma leitura das publicações - literatura de base e o setor vitivinícola - para compreender se elas colaboram para o desenvolvimento sustentado da vitivinícola brasileira e seu estabelecimento enquanto recurso natural, particularidade do produto, terroir e manutenção de práticas culturais na elaboração de vinhos.

Apresenta-se, assim, a importância dessas normas para o sistema de Indicação Geográfica brasileiro, a necessidade de normas técnicas, como elas surgiram, como funcionam, como foram construídas e qual o principal impacto delas no desenvolvimento sustentado da IG no setor vitivinícola, a partir da forçada IG para o setor e a potencialidade desse reconhecimento para, então, analisar os resultados das normas técnicas e de sua importância para o setor. 


\section{CONSIDERAÇÕES FINAIS}

A partir do exposto anteriormente, verifica-se um ganho por meio da elaboração das normas publicadas e daquelas que estão em fase de publicação. Dessa forma, foi possível sistematizar as melhores práticas de estruturação, gestão e controle das IGs disponíveis no Brasil. Além de publicações científicas, esse material, sistematizado por um grande grupo de especialistas, não era disponível para os principais interessados: os produtores da IG.

Em face da parceria realizada entre a ABNT e o SEBRAE, essa confluência de pessoas com um propósito comum foi possível, e as normas já publicadas são os resultados mais expressivos. A sua incorporação e uso por aqueles que objetivam trabalhar pelo reconhecimento de regiões delimitadas depende muito da divulgação desse trabalho.

Atualmente, três iniciativas relacionadas às IGs vitivinícolas estão em andamento e já têm levado em consideração o disposto nas referidas normas técnicas. A IP Campanha Gaúcha e a IP Vale do São Francisco se encontram em adiantado estado de estruturação. O projeto para a DO Altos de Pinto Bandeira já inicia com essa percepção.

Certamente, após a finalização desses processos, será possível verificar de forma mais efetiva a aplicabilidade dessas normas no setor vitivinícola, proposta que se destina a trabalhos futuros.

\section{REFERÊNCIAS BIBLIOGRÁFICAS}

ASSOCIAÇÃO BRASILEIRA DE NORMAS TÉCNICAS - ABNT. A importância da normalização MPE. [sem data de publicação]. Disponível em: <http://abnt.org. $\mathrm{br} /$ paginampe/biblioteca/files/upload/anexos/pdf/d0240c42bc0acbc9d55e958d0a8cb6af.pdf>. Acesso em: 27 dez. 2016.

. NBR 16479: Indicação Geográfica - Terminologia. Rio de Janeiro: ABNT, 2016a. 5 p.

. NBR 16536. Indicação geográfica - Orientações para estruturação de indicação. Rio de Janeiro: ABNT, 2016b. 17 p.

BOWEN, S. Embedding local places in global spaces: Geographical indications as a territorial development strategy. Rural Sociology, v. 75, n. 2, p. 209-243, 2010. 
BRASIL. Lei no 9.279, de 14 de maio de 1996. Regula direitos e obrigações relativos à propriedade industrial. Diário Oficial [da] República Federativa do Brasil. Brasília, DF, 15 de maio de 1996. Disponível em: <http://www.planalto.gov.br/ ccivil_03/leis/L9279.htm.> Acesso em: 04 mar. 2017.

. Ministério do Desenvolvimento, Indústria e Comércio Exterior. Instituto Nacional da Propriedade Industrial. Consulte os registros já concedidos e os pedidos em andamento. Publicado em novembro de 2002. Disponível em: <http:// www.inpi.gov.br/menu-servicos/indicacao-geografica/pedidos-de-indicacao-geografica-no-brasil>. Acesso em: 01 maio 2017.

. Ministério do Desenvolvimento, Indústria e Comércio Exterior. Instituto Nacional da Propriedade Industrial. Instrução Normativa no 25/2013. Estabelece as condições para o registro de Indicações Geográficas. Brasília, DF: MDIC/ INPI, 21 ago. 2013.

BRUCH, K. L. Signos distintivos de origem: entre o velho e novo mundo vitivinícola. 1. ed. Passo Fundo: Editora IMED, 2013. 320 p.

BRUCH, K. L.; VITROLLES, D.; LOCATELLI, L. Estudo de Caso: IP Vale dos Vinhedos, IP Paraty e IP Vale do Submédio do São Francisco. IN: BRASIL. Ministério da Agricultura, Pecuária e Abastecimento. Curso de propriedade intelectual \& inovação no agronegócio: Módulo II, indicação geográfica. Organização de Luiz Otávio Pimentel. 4. ed. - Brasília: MAPA; Florianópolis: FUNJAB, 2014, p. 296-333.

CERDAN, C. M. T. et al. Indicação Geográfica de produtos agropecuários: importância histórica e atual. In: BRASIL. Ministério da Agricultura, Pecuária e Abastecimento. Curso de propriedade intelectual \& inovação no agronegócio: Módulo II, indicação geográfica. Organização Luiz Otávio Pimentel. 4. ed. Brasília: MAPA; Florianópolis: FUNJAB, 2014, p. 32-58.

FLORES, M. A identidade cultural do território como base de estratégias de desenvolvimento - uma visão do estado da arte. Territorios con Identidad Cultural. 20 RIMISP. Março, 2006. 47 p. Disponível em: <http://indicadores.fecam.org. br/uploads/28/arquivos/4069_FLORES_M_Identidade_Territorial_como_Base_ as_Estrategias_Desenvolvimento.pdf>. Acesso em: 23 maio 2017.

GASPAR, L. C. M. Potencialidades e estratégias para o mel de abelha do Estado do Rio de Janeiro: análise prospectiva para valorização por meio dos sinais distintivos do comércio. 2015. Dissertação (Mestrado Profissional em Propriedade Intelectual e Inovação) - Academia de Propriedade Intelectual, Inovação 
e Desenvolvimento, Coordenação de Programas de Pós-Graduação e Pesquisa, Instituto Nacional da Propriedade Industrial - INPI, Rio de Janeiro, 2015.

ILBERY, B. et al. Product, Process and Place: An Examination of Food Marketing and Labelling Schemes in Europe and North America. European Urban and Regional Studies, v. 12, n. 2, p. 116-132, 2005.

LOCATELLI, L. Indicações Geográficas e Desenvolvimento Econômico. In. BARRAL, W.; PIMENTEL, L. O. (Org.). Propriedade intelectual e desenvolvimento. Florianópolis: Fundação Boiteux, 2007.

LOCATELLI, L.; SOUZA, K. A proteção jurídica e o processo de reconhecimento das indicações geográficas no Brasil: aspectos introdutórios. In: LOCATELLI, L. (Org.). Indicações geográficas: desafios e perspectivas nos 20 anos da Lei de Propriedade Industrial. Rio de Janeiro: Lumen Juris, 2016, p. 3-16.

NIEDERLE, P. A. Indicações geográficas e processos de qualificação nos mercados agroalimentares. In: NIEDERLE, P. A. (Org.). Indicações geográficas: qualidade e origem nos mercados alimentares. Porto Alegre: UFRGS, 2013, p. 23-54.

. Controvérsias sobre a noção de Indicações Geográficas enquanto instrumento de desenvolvimento territorial: a experiência do Vale dos Vinhedos em questão. In: CONGRESSO SOCIEDADE BRASILEIRA DE ECONOMIA, ADMINISTRAÇÃO E SOCIOLOGIA RURAL, 47., Porto Alegre, 2009. Anais... Porto Alegre: SOBER, 2009.

OLIVEIRA, M. C. Normalização e MPE: um caminho sem volta. Boletim ABNT, abril, 2013. Disponível em: <http://abnt.org.br/paginampe/biblioteca/files/ upload/anexos/pdf/04818c3f3916ca5b8d17e8033febcd47.pdf>. Acesso em: 27 dez. 2016.

PECQUEUR, B. Qualité e développement territorial: I' hyphotès e dupannier de biens et de services territorialisés. Economie Rurale, Paris, n. 261, 2001.

. A guinada territorial da economia global. Política e Sociedade, n. 14, p. 79-105, abr. 2009.

PELLIN, V.; VIEIRA, A. C. P. Indicações geográficas no Brasil: uma perspectiva pro-registro. In: LOCATELLI, L. (Org.). Indicações geográficas: desafios e perspectivas nos 20 anos da Lei de Propriedade Industrial. Rio de Janeiro: Lumen Juris, 2016, p. 89-112.

SERVIÇO BRASILEIRO DE APOIO ÀS MICRO E PEQUENAS EMPRESAS - SEBRAE. Parceria ABNT/SEBRAE Normalização e Pequenos Negócios. São Paulo: SEBRAE/ 
ABNT, 2015. Disponível em: <https://www.google.com.br/url?sa=t\&rct=j\&$q=\& e s r c=s \&$ source $=$ web\& $c d=3 \& c a d=r j a \&$ uact $=8 \&$ ved $=0$ ahUKEwj2707rweTRAhXDHJAKHcKFAbUQFggvMAI\&url=http\%3A\%2F\%2Fwww.abnt.org. br\%2Feventos\%2Fapresentacoes\%2Fcategory\%2F137-workshop-internacional-sobre-normalizacao-e-pequenos-negocios\%3Fdownload\%3D319\%3Aparceria-abnt-sebrae\&usg=AFQjCNFIWxqUUFKIW3ToZGwLmZGTBJNMZw\&sig2=OLY6svwxnSueC1yfDCYKuA\&bvm=bv.145822982,d.Y2l>. Acesso em: 26 dez. 2016.

SOAM, S. K.; HUSSAIN, M. Commercialization of indigenous health drinks as geographical indications. Journal of Intellectual Property Rights, v. 16, n. 2, p. 170-175, 2011.

VIEIRA, A. C. P.; BUAINAIN, A. M.; BRUCH, K. L. A indicação geográfica como estratégia para minimizar a assimetria de informação. In: BUAINAIN, A. M.; CASTRO, A. C.; BONACELLI, M. B. M. (Orgs.). Propriedade intelectual e inovações na agricultura. Vol. 1. Rio de Janeiro: Ideia, 2015.

VIEIRA, A. C. P.; PELLIN, V. Indicações geográficas como políticas públicas de desenvolvimento territorial - o caso dos Vales da Uva Goethe. In: DALLABRIDA, V. R. (Org.). Indicação geográfica e o desenvolvimento territorial: reflexões sobre o tema e potencialidades no Estado de Santa Catarina. 1. ed. São Paulo: LiberArs, 2015, p. 273-288.

VIEIRA, A. C. P.; WATANABE, M.; BRUCH, K. L. Perspectivas de desenvolvimento da vitivinicultura em face do reconhecimento da Indicação de Procedência dos Vales da Uva Goethe. Revista GEINTEC, v. 2, p. 327-343, 2012.

VIEIRA, A. C. P.; ZILLI, J. C.; BRUCH, K. L. As políticas públicas como instrumento para o desenvolvimento das indicações geográficas: o caso dos Vales da Uva Goethe em Urussanga, Santa Catarina In: SEMINÁRIO INTERNACIONAL DE DeSEnVOlVIMENTO REgIONAL, 7., Santa Cruz do Sul, 2015. Anais... Santa Cruz do Sul: UNISC, v. 1, 2015.

WILKINSON, J. Mercados, redes e valores: o novo mundo da agricultura familiar. Porto Alegre: UFRGS, 2008. 